\title{
Nitrite-Enhanced Charge Transfer to and from Single Polyaniline Nanotubes
}

Jianyun Liu ${ }^{a, b}$, Xiuting Li $i^{b}$, Christopher Batchelor-McAuley ${ }^{b}$, Guodong Zhu ${ }^{a}$, Richard G.

$$
\text { Compton }^{b *}
$$

${ }^{a}$ State Environmental Protection Engineering Center for Pollution Treatment and Control in the Textile Industry, College of Environmental Science and Engineering, Donghua University, Shanghai 201620, P. R. China

${ }^{\mathrm{b}}$ Department of Chemistry, Physical \& Theoretical Chemistry Laboratory, University of Oxford, Oxford OX1 3QZ, United Kingdom

\section{*Corresponding Author: Email: Richard.compton@chem.ox.ac.uk}

\section{ABSTRACT}

As reported previously (Applied Materials Today 2017, 7, 239-245), the charge transfer to partially oxidized PANI nanotubes in electrochemical reactions is heavily limited due to the non-conductivity of the reduction/oxidation products. In this paper, the doping level of individual polyaniline (PANI) nanotubes was substantially enhanced using nitrite as an electron acceptor in sulphuric acid aqueous solution as recorded by the nano-impact method. The charge transferred to one single tube during reduction process is close to the theoretical value of $170 \pm 112 \mathrm{pC}$ per tube (assuming 2-electron reduction for the PANI tubes studied), while the charge during PANI oxidation is dramatically decreased. Reaction processes are proposed based on the oxidative properties of nitrite in acid solution. Ultraviolet-visible spectroscopy analysis further confirms an oxidation-reduction reaction between PANI and nitrite. In contrast the electrochemical reaction of ensembles $\left(21 \mu \mathrm{g} \mathrm{cm}^{-1}\right)$ of PANI tubes on glassy carbon electrodes simply show limited electro-catalytic activity. 


\section{Introduction}

Polyaniline (PANI) is the oldest and potentially one of the most useful electronic/conducting polymers because of its facile synthesis, remarkable stability and unique acid/base doping/dedoping chemistry. The polyanilines can be synthesized by either chemical oxidation or electrochemical polymerization of aniline under mild conditions. Especially with the rapid appearance of nanoscience and nanotechnology in recent years, the nanostructured PANI, such as nanofibers ${ }^{[1]}$, nanospheres ${ }^{[2]}$, and nanotubes ${ }^{[3]}$, has attracted much attention due to high surface area, good doping and superior proccessiblity, compared to conventional bulk PANI ${ }^{[1 c]}$. Usually, the PANIs exist in three redox states, the completely reduced state 'leucoemeraldine' (Leuco), the half oxidized state 'emeraldine' (Em) and the completely oxidized state 'pernigraniline' $(\mathrm{Per})^{[4]}$. Scheme 1 shows the structures of various oxidation states of PANI, acid doping/dedoping and redox chemistry (4 anilines as one repeat unit). The conductivity of PANI is switchable by changing either the protonation state or the oxidation state ${ }^{[5]}$. For example, in the Em oxidation state, PANI becomes electrically conducting when doped with an acid (i.e. Em.salt), with a huge increase in conductivity of about $10^{10}$, compared with the Em base ${ }^{[6]}$.

It is well known that PANI presents two pairs of quasi-reversible redox peaks in the cyclic voltammograms of PANI in acid solution, involving charge transfer processes between three redox forms of PANI including fully oxidized Per, the intermediate conducting state Em.salt and the fully reduced leucoemeraldine ${ }^{[6-7]}$. A 2-electron transfer occurs in each redox reaction for one repeat unit (Scheme 1). The reversible transition of various redox states achieved by doping is the key to maintain reversible conductivity. The recoverable conductivity makes PANI a promising material for many applications including rechargeable batteries ${ }^{[8]}$, chemical sensor ${ }^{[9]}$, capacitive energy storage ${ }^{[10]}$, and electro-optic and electrochromic 
devices $^{[1 c, 11]}$. However, during the application in electrical devices, the specific charge and doping extent of PANI and utilization efficacy in PANI nanomaterials has rarely been taken into consideration. In a previous study, we found that the doping level of PANI ensembles across the electrode can be only $6 \%$, whilst that of individual PANI tubes is $17 \%$, by comparison with the theoretical expected charge per PANI tube assuming 2-electron doping from the intermediate conductive state Em.salt form to Leuco form as shown in Scheme 1, which indicates the material utilization efficacy is tiny ${ }^{[7 a]}$. In the study, upon impact at the electrode surface, single PANI tubes are partially and locally converted from the conducting emeraldine form to non-conducting states (leucoemeraldine or pernigraniline). This change in conductivity due to the altered oxidation state hence inhibits further electron transfer to the distant materials of the single tube ${ }^{[7 a]}$. Therefore, it is of importance to develop an effective way in order to enhance the oxidation and improve the doping level of PANI nanomaterials in exploring the application of PANI electronic devices.

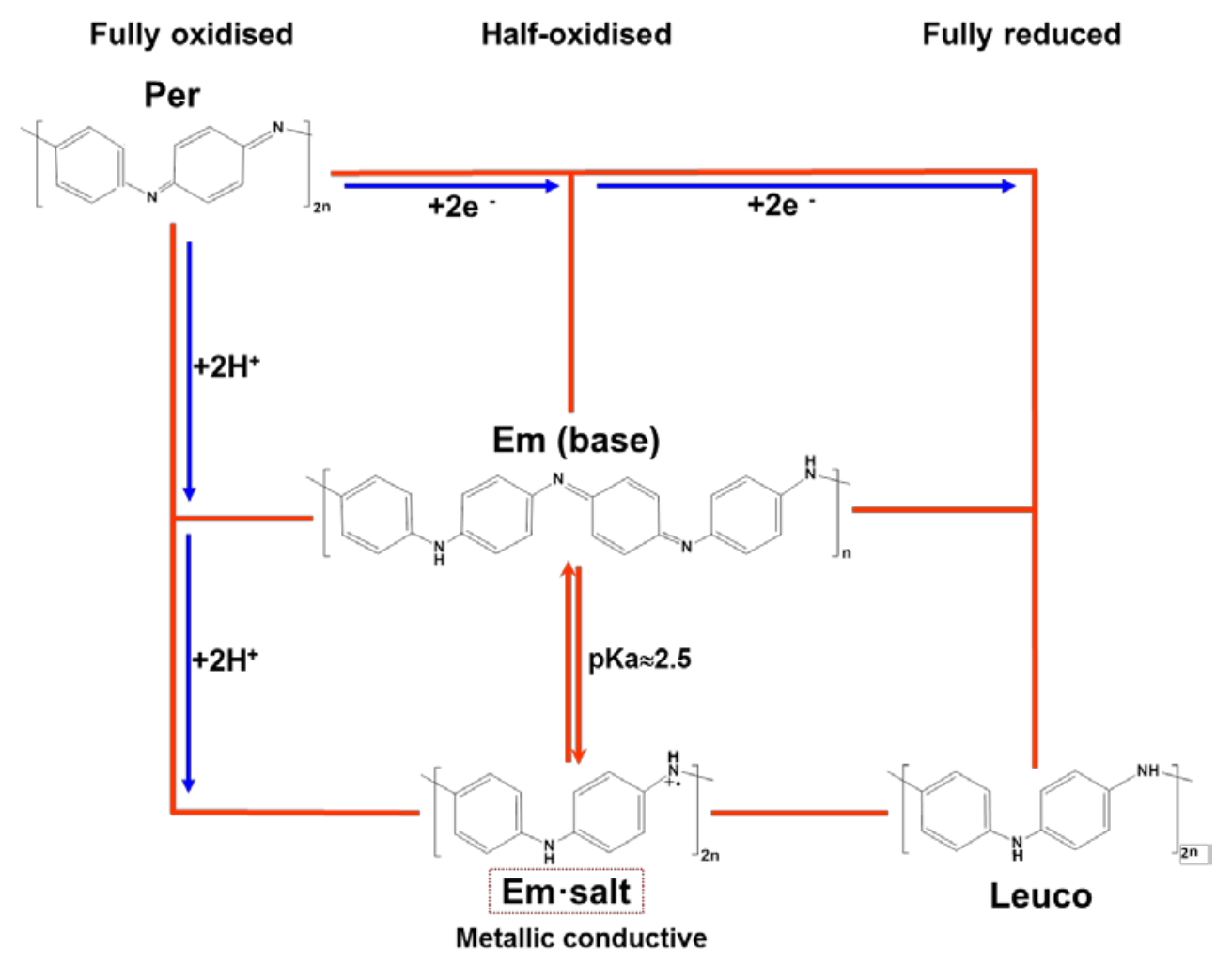


Scheme 1 Diagram showing the different protonation and oxidation degrees of PANI. The horizontal direction in the square represents the degree of oxidation, and the vertical direction represents the degree of protonation.

Some oxidant species for PANI including $\mathrm{HAuCl}_{4}{ }^{[1 \mathrm{~b}, 12]}, \mathrm{Ag}^{+[13]}$ and persulfate ${ }^{[14]}$ have been reported previously. Nitrite, as an electron acceptor, has been applied in food science and bio-system ${ }^{[15]}$. The reaction between the product of the electron transfer and the respective nitrogen oxyacids or oxyanions has also been studied ${ }^{[16]}$. There are several reports about the nitrite-polyaniline system, but only the electrocatalytic reduction of nitrite is reported based on the PANI ensembles modified bulk electrode ${ }^{[17]}$. The chemical interaction of nitrite and PANI has not been reported before.

In this report, the doping level of PANI nanotube on a carbon fibre micro wire electrode is studied by the nano impact method ${ }^{[18]}$, for the first time, using nitrite as oxidant in a PANI nanotube suspension. The electron transfer process at different potentials is investigated. A chemical reaction of nitrite-emeraldine is proposed in light of chronoamperometry and UVVis spectrometry.

\section{Results and discussion}

In this section, the electrochemical behaviour of PANI nanotube ensembles coated on a bulk glassy carbon electrode (GCE) is investigated in the presence of nitrite via cyclic voltammetry and an apparent catalytic reaction process is discussed. Subsequently, nanoimpact chronoamperometry is employed to compare the doping level of single nanotubes in the presence and absence of nitrite. The nitrite-initiated doping promotion of PANI single nanotubes is discussed and the related mechanism is addressed. Finally, UV-Vis spectroscopy is carried out to confirm the interaction of nitrite and PANI. 

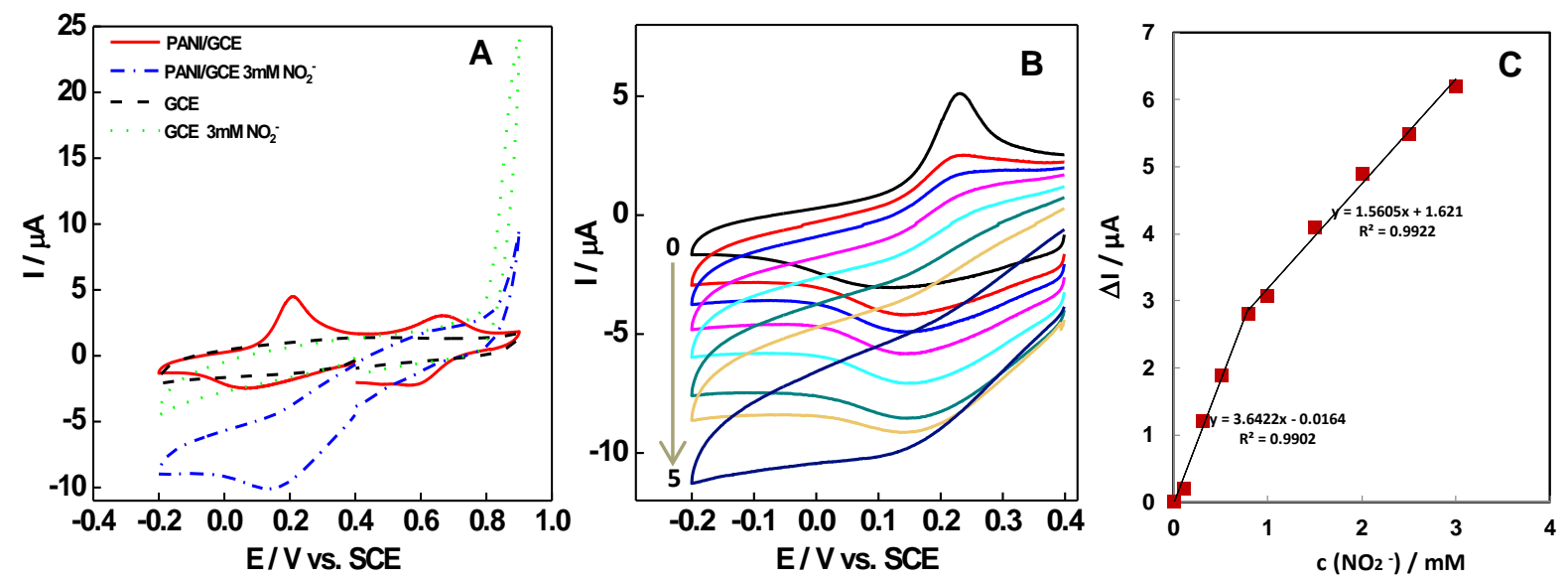

Figure $1 \mathrm{~A}$ ). CVs of PANI/GCE and bare GCE in $0.2 \mathrm{M} \mathrm{HSO}_{4}$ solution in the presence and absence of $3 \mathrm{mM}$ nitrite. $20 \mathrm{mV} / \mathrm{s}$. B) CVs of PANI/GCE in $0.2 \mathrm{M} \mathrm{HSO}_{4}$ solution containing 0, 0.3, 0.5, 0.8, 1.5, 2.5, 3 and $5 \mathrm{mM}$ nitrite. C) Relationship of peak current with the concentrations of nitrite at the PANI/GCE.

The as-prepared PANI nanotube exists in its conducting Em.salt state ${ }^{[7 a]}$. Cyclic voltammetry was carried out (Figure 1). The initial potential of the CV scan starts from the open circuit potential (OCP) of $0.41 \mathrm{~V}$. The solid line in Figure 1A shows a typical redox characteristic of the emeraldine salt form on a PANI nanotube coated electrode surface. The two pairs of redox peaks centred at around 0.1 and $0.7 \mathrm{~V}$ correspond to leucoemeraldine/emeraldine and emeraldine/pernigraniline redox transitions, respectively. A 2-electron transfer occurs in each redox reaction for one repeat unit (composed of 4 anilines) in light of the PANI structure in Scheme $1^{[5,19]}$. Upon addition of nitrite, the cathodic peak current at a potential of round $0.15 \mathrm{~V}$ increases while the corresponding oxidation peak current is depressed upon reverse scan. At the same time there is very limited increase in the background current on a bare GCE in the negative potential domain after addition of nitrite compared with one in the absence of nitrite. With increasing nitrite concentration, the cathodic peak current increases, and a steady enhancement of the reduction current with the concentration of nitrite is found over the range of $0.3 \sim 3 \mathrm{mM}$ (see Figure 1B). Furthermore there is a monotonic relationship between the current and concentration of nitrite (Figure 1C). Therefore, the electrocatalytic reduction of 
nitrite might be surmised to occur, which is consistent with the reported electrocatalytic reduction of nitrite on a traditional PANI modified bulk electrode ${ }^{[17 a, 20]}$. However, the emeraldine/pernigraniline redox transition in the positive potential domain is depressed (Figure 1A) in the presence of nitrite, different to that seen for the case of the electropolymerized PANI modified electrode ${ }^{[17 a]}$. Meanwhile, the oxidation current of nitrite is significantly decreased on the PANI nanotube ensembles coated GCE, compared with a strong oxidation signal on a bare GCE in nitrite-containing electrolyte solution, and the onset potential of nitrite oxidation shifts positively from $0.76 \mathrm{~V}$ to $0.82 \mathrm{~V}$. It may be surmised that a chemical interaction between nitrite and emeraldine occurs in acidic solution, which results in the attenuation of the electrochemical oxidation reaction. This influence of this chemical reaction on charge transfer of PANI can be clearly revealed via nano-impact method using chronoamperometric technique, as described in the next section.

Nitrite-promoted reduction doping of PANI single nanotubes
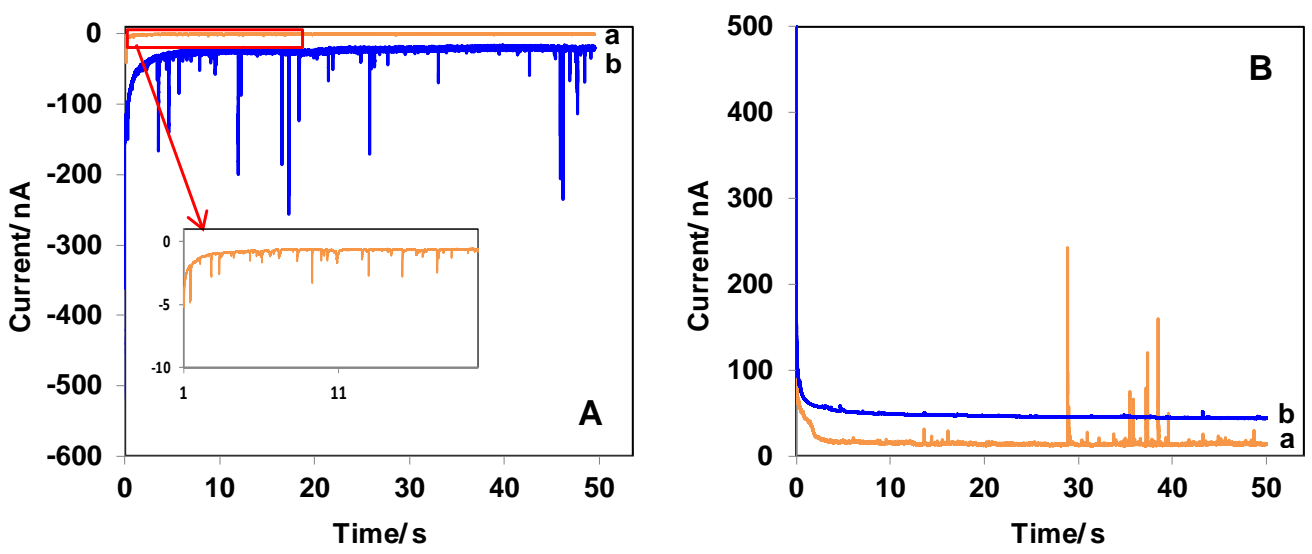

Figure 2 Representative chronoamperometric scans at a cylindrical carbon fibre wire electrode in 0.2 $\mathrm{M} \mathrm{HSO}_{4}$ solution containing $0.02 \mathrm{~g} \mathrm{~L}^{-1}$ PANI nanotube suspension in the absence (orange) and presence (blue) of $3 \mathrm{mM}$ nitrite (A) $-0.2 \mathrm{~V}$, (B) $0.8 \mathrm{~V}$. Inset of (A) is the magnification of chronoamperometric scan in the absence of nitrite. 
The chronoamperometric nano-impact method reflects more clearly the electron transfer of individual PANI nanotubes. Figure 2A presents representative chronoamperograms recorded at a carbon fibre micro wire electrode at $-0.2 \mathrm{~V}$ in a deaerated $0.2 \mathrm{M} \mathrm{H}_{2} \mathrm{SO}_{4}$ aqueous solution containing $0.02 \mathrm{~g} \mathrm{~L}^{-1}$ PANI nanotube in the absence (curve a) and presence (curve b) of nitrite. From the magnification inset of curve a, some small and clear spikes in the current transients were observed, which is consistent with the reduction of the conductive 'halfoxidized' emeraldine PANI observed in the cyclic voltammograms. The average charge from a total of 406 spikes in 58 scans is found to be $37 \pm 4.2 \mathrm{pC}$ at $-0.2 \mathrm{~V}$, which is much less than the expected charge of an individual PANI nanotube of $171 \pm 112 \mathrm{pC}$ (assuming 2-electron transfer from the initial emeraldine to fully reduced state leucoemeraldine, detailed calculation was shown in the Experimental Section, $)^{[7 a]}$. In particular, the charge transferred becomes less and less when applying a more negative potential. This is likely due to the loss of the electrical contact during the transition of metallic emeraldine salt from a conducting form to an insulating form of PANI, thus blocking further electron transfer. Therefore, most of the PANI molecules are inert inside the nanomaterials. However, upon addition of nitrite in the PANI nanotube suspension solution, a series of well-resolved spikes are observed (curve b of Figure 2A). The corresponding average current from a total of 422 spikes in 54 scans is round $43 \pm 4.6 \mathrm{nA}$. If a simple catalytic reduction reaction of nitrite occurs upon individual PANI nanotubes colliding with the carbon micro wire electrode, the maximum limiting current $\left(I_{m}\right)$ of nitrite can be estimated as follows ${ }^{[21]}$ :

$I_{m}=n F \pi \operatorname{Dclf}(\tau)$

$\tau=\frac{D t}{r_{0}^{2}}$

$f(\tau)=\frac{e^{-\sqrt{\pi \tau} / 10}}{\sqrt{\pi \tau}}+\frac{1}{\operatorname{Ln}\left[\left(4 \tau e^{-\gamma}\right)^{1 / 2}+e^{5 / 3}\right]}$ 
where, $D=1.6 \times 10^{-5} \mathrm{~cm}^{2} \mathrm{~s}^{-1}$ (diffusion coefficient of nitrite in aqueous solution), $n$ is the number of electrons transferred per nitrite molecules during reduction on the nanotube, where $\mathrm{n}=1[8,9], \mathrm{r}_{0}(0.2 \pm 0.02 \mu \mathrm{m})$ and $l(2.9 \pm 1.9 \mu \mathrm{m})$ represent respectively, the radius and length of one single PANI nanotube, which were measured by SEM previously ${ }^{[7 a]}$. Assuming the duration time of spikes of $10 \mathrm{~ms}, I_{m}$ is then calculated to be $1.2 \mathrm{nA}^{[21]}$. However, the measured average spike current $(43 \pm 4.6 \mathrm{nA})$ in chronoamperograms is significantly higher than the calculated catalytic current. This implies that the spike current is not simply from the charge transfer of nitrite reduction. Instead an alternative explanation is addressed next.

According to the redox properties of the as-synthesized intermediate redox state PANI, it can be either reduced at negative potential or oxidized at positive potential as shown in Scheme $1^{[19]}$. The effect of nitrite on the electron transfer of an emeraldine PANI at an oxidation potential of PANI nanotube is investigated. Figure 2B shows the chronoamperograms of carbon fibre micro wire electrode at $0.8 \mathrm{~V}$ in $0.02 \mathrm{~g} \mathrm{~L}^{-1}$ PANI nanotube in the absence (curve a) and presence (curve b) of nitrite. Upon addition of nitrite, the spike currents decline substantially, in contrast with the current variation in the negative potential domain. It indicates that the interaction of nitrite and PANI tube in the solution depresses the electrochemical oxidation of emeraldine-state PANI. Note that CV of the dropcast PANI in Figure 1A (red line) has shown that at $0.8 \mathrm{~V}$ there is no overoxidation and hydrolysis of PANI on the experimental time scale.

Chronoamperometric experiments at various potentials were further carried out, ranging within the reduction potential window from +0.1 to $-0.5 \mathrm{~V}$ and the oxidation potential window from 0.2 to $+0.8 \mathrm{~V}$ in a PANI nanotube suspension both with and without nitrite. The scan was repeated at each potential until a large sample size (n, the number of spikes) is obtained for statistics. Representative chronoamperograms at $-0.1,-0.3$ and $-0.5 \mathrm{~V}$ are shown 
in Figure S1 in the supporting materials. Clearly, the spike current increases with increasing the reduction over-potential. The average charge passed per spike $(\mathrm{Q})$ is plotted against the applied potential, as shown in Figure 3. The blue diamond line in Figure 3 presents the charge variation with potential in a PANI suspension in the absence of nitrite. The spike current appears at the potential of $0 \mathrm{~V}$ in the absence of nitrite, indicating the onset potential for PANI reduction. A very low charge, especially at more negative overpotential is observed, indicating the termination of charge transfer along the tube due to the decrease of tube conductivity upon reduction ${ }^{[7 a]}$. The red square line in Figure 3 presents the charge variation with potential after addition of nitrite in a PANI suspension. Compared with the spike charge of PANI tubes without nitrite, there is a marked increase in charge with increasing the reduction overpotential. And the onset potential for the appearance of the spikes shifts to 0.1 $\mathrm{V}$, indicating the facile electron transportation on the PANI tube in the presence of nitrite. The average charge of $460 \pm 56 \mathrm{pC}$ is achieved at $-0.5 \mathrm{~V}$, which is comparable to the theoretical charge per PANI tube (171 $\pm 112 \mathrm{pC})$, considering the calculation error of PANI tube length and roughness. It is worth noting that the charge transferred in the oxidation zone is reduced greatly, indicating the charge transfer between emeraldine to pernigraniline PANI is heavily depressed. 


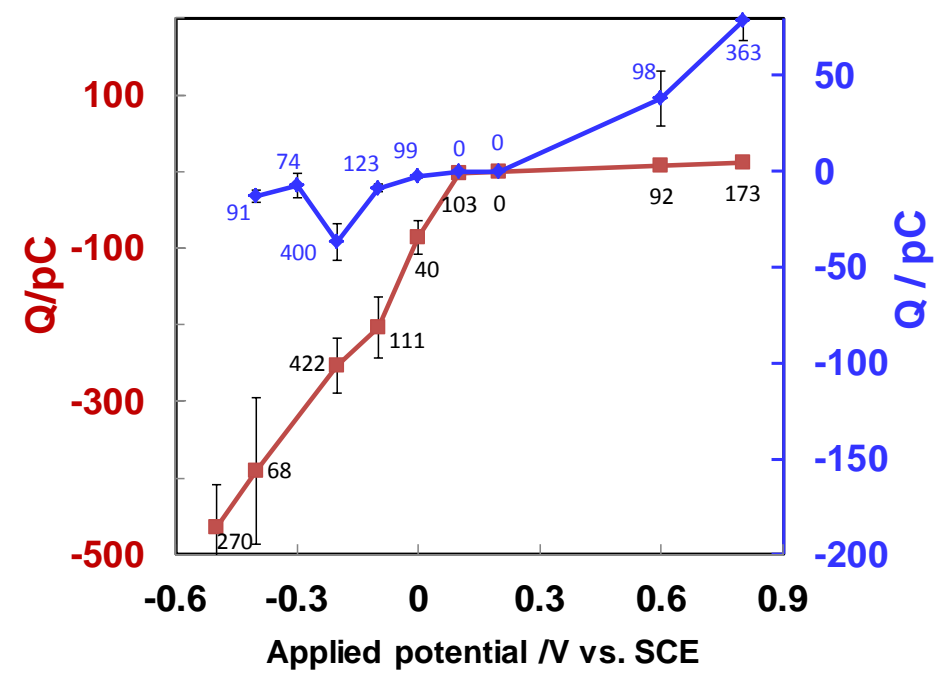

Figure 3 Average charge transferred per individual impact spike (Q) as a function of applied potentials in the absence (diamond) and presence (square) of $3 \mathrm{mM}$ nitrite. The error of the average charge is obtained from $\mathrm{SD} /(\mathrm{n})^{1 / 2}$, where $\mathrm{SD}$ is the standard deviation and $\mathrm{n}$ is the number of spikes.

These differences of charge transferred during redox processes of PANI tubes in the presence of nitrite are explained according to the chemical reaction processes (a-d) in Scheme 2.
(a) Em.salt $+2 \mathrm{ne}^{-} \longrightarrow$ Leuco
(b) Leuco $+2 \mathrm{nHNO}_{2}+2 \mathrm{nH}^{+} \longrightarrow$ Em.salt $+2 \mathrm{nNO}+2 \mathrm{nH}_{2} \mathrm{O}$
(c) Em.salt $+2 \mathrm{nHNO}_{2} \longrightarrow \mathrm{Per}+2 \mathrm{nNO}+2 \mathrm{nH}_{2} \mathrm{O}+2 \mathrm{nH}^{+}$
(d) $\mathrm{Per}+4 \mathrm{nH}^{+}+2 \mathrm{ne} \longrightarrow$ Em.salt

Scheme 2 Redox reaction process of PANI in the absence (a) and presence (a-d) of nitrite. Em, leuco and Per represent the half-oxidized conducting form, fully reduced form and fully oxidized form of PANI, respectively. Note that a simplified reaction scheme is proposed here by stating NO as the product of the reaction. In reality, the reaction scheme is usually much more complicated. ${ }^{[17]}$

In the absence of nitrite, the redox reaction of PANI nanotube upon colliding with the carbon fibre wire electrode is expressed in equation (a) of Scheme 2. The reaction stops with the formation of the insulating leuco form ${ }^{[7 a]}$. Therefore, the doping level of PANI is very 
low. In the presence of nitrite, however, the complex multiple reactions in equation (a) to (d) likely occur in the presence of nitrite. Reactions (a) and (b) are similar to the electrocatalytic reduction of nitrite. On the other hand, Em.salt state of PANI in the PANI-nitrite mixture is possibly oxidized into Per (reaction c), and the resulting Per is reduced electrochemically upon collision with carbon fibre micro wire electrode where the negative potential is applied (reaction d), and thus contributing to the charge of spikes. Nitrite not only enhances the charge transfer by electrocatalytic reduction, but also makes the charge transfer possible from the fully oxidized Per into conducting Em.salt. Therefore, the doping level of PANI is much enhanced due to the facile electron transfer along the conducting PANI companying with the chemical reduction and electrocatalytic reduction of nitrite in the PANI-nitrite mixture system. In the contrast, the oxidation spikes are decreased greatly due to the exhaustion of Em.salt to the fully oxidation state Per in the chemical reaction (c). This is consistent with the experimentally observed disappearance of redox peak at $+0.62 \mathrm{~V}$ in the cyclic voltrammograms (Figure 1A).

\section{Interaction of PANI and nitrite studied by UV-Vis spectrometry}

The freshly prepared green PANI nanotubes in $0.2 \mathrm{M} \mathrm{H}_{2} \mathrm{SO}_{4}$ aqueous solution exist in the protonated emeraldine form. The UV-Vis absorption spectrum of PANI nanotubes reveals two typical absorption bands centred at $410 \mathrm{~nm}$ and $800 \mathrm{~nm}$ as shown in the dotted line of Figure 4. These two absorption bands are the characteristic of the protonated form of PANI tube under acidic condition, indicating the presence of polarons (radical cations) as shown in scheme $1^{[22]}$. Upon addition of nitrite, the series of absorption bands between $340 \mathrm{~nm}$ and 390 nm appear, related to the absorption of nitrogen involved species, as evidenced by a control experiment (bottom line) in nitrite-containing $0.2 \mathrm{M} \mathrm{H}_{2} \mathrm{SO}_{4}$ aqueous solution ${ }^{[23]}$. The absorption peak at $800 \mathrm{~nm}$ has a blue shift (red solid line) to around $700 \mathrm{~nm}$, which results from the oxidation of the amine units in emeraldine forming the pernigraniline, a complete 
quinoid form, in the presence of the nitrite at the $\mathrm{pH}$ of study ${ }^{[19,22 \mathrm{~b}]}$. It is also observed that the absorbance at $700 \mathrm{~nm}$ decreases with the reaction time. This may be attributed to the relative slow hydrolysis of the pernigraniline form ${ }^{[14]}$. These observations confirm that a redox reaction between emeraldine and nitrite occurs, and the fully oxidized PANI is formed in the $\mathrm{HNO}_{2}$-containing $\mathrm{H}_{2} \mathrm{SO}_{4}$ aqueous solution.

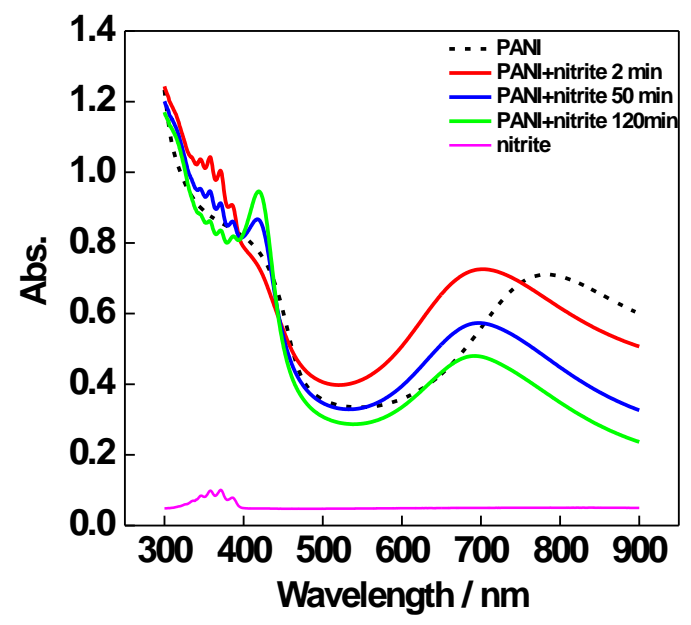

Figure $4 \mathrm{UV}$-Vis spectra of PANI suspension in $0.2 \mathrm{M} \mathrm{HSO}_{4}$ solution before (dotted line) and after addition (solid line) of $3 \mathrm{mM}$ nitrite with various reaction time. The bottom line is the spectrum of 2 $\mathrm{mM}$ nitrite in $0.2 \mathrm{M} \mathrm{HSO}_{4}$ solution.

\section{Conclusions}

In summary, the electrochemical activity of individual PANI tubes is quenched upon collision with carbon fibre micro wire electrode in the nano-impact studies, when a negative potential is applied, due to the formation of insulating leucoemeraldine state. In contrast, the electron doping of PANI tube is substantially enhanced with nitrite as an oxidant. The electrochemical catalytic reaction of nitrite in company with the chemical redox reaction between PANI and nitrite makes the doping process of conducting PANI proceed continuously and thoroughly in the nitrite-PANI system. The related chemicalelectrochemical reaction mechanism is proposed, and UV-Vis analysis further confirms 
formation of the fully oxidized PANI due to oxidative properties of nitrite. However, only the common electrocatalytic reduction of nitrite is found on the PANI ensembles modified bulk electrode. The nano impact method presents the electrochemical process more precisely than ensembles on the bulk electrode.

\section{Experimental section:}

\section{Materials}

Aniline (reagent grade) was purchased from Sigma-Aldrich and was used as received. Potassium nitrite and the other chemicals were received from Sigma-Aldrich and were of analytical grade. All aqueous solutions were prepared with ultrapure deionized water (18.2 $\mathrm{M} \Omega$, Millipore, Billerica, $\left.\mathrm{MA}, 25^{\circ} \mathrm{C}\right)$.

A glassy carbon working electrode (GCE) with a diameter of $3 \mathrm{~mm}$ was supplied by $\mathrm{CH}$ instruments (Austin, TX, USA). Carbon fibre micro wire electrodes (length of $1 \mathrm{~cm}$, diameter of $7 \mu \mathrm{m}$ ) were home-made and the detailed fabrication procedure was described previously [7a, 21b].

Polyaniline (PANI) hollow fibres were fabricated using a previously described method ${ }^{[2 b \text {, }}$ 7a, 9c]. The detailed procedures are described in the Supporting Information.

Preparation of the PANI nanotube suspension and calculation of the theoretical charge per tube

The PANI suspension solution for bulk electrode modification was prepared by mixing $3.0 \mathrm{mg}$ of the hollow fibres with $10 \mathrm{~mL}$ pure water and sonicating via a Fisher Scientific ultrasonic bath S60 (230 V 50/60 Hz 150W) for $60 \mathrm{~min}\left(<40^{\circ} \mathrm{C}\right)$ to break up the long fibres 
into shorter nanotubes. For nano-impact experiments, a $0.02 \mathrm{~g} \mathrm{~L}^{-1}$ PANI suspension in $0.2 \mathrm{M}$ $\mathrm{H}_{2} \mathrm{SO}_{4}$ was prepared by mixing the hollow fibres with $0.2 \mathrm{M} \mathrm{H}_{2} \mathrm{SO}_{4}$ solution followed by sonication for $60 \mathrm{~min}$. The average size of the nanotubes was estimated to be $2.89 \pm 1.9 \mu \mathrm{m}$ length and $0.39 \pm 0.06 \mu \mathrm{m}$ width, as measured by SEM previously ${ }^{[7 \mathrm{a}]}$. Thus, the average volume of one nanotube $V_{\text {tube }}$ is estimated to be $(2.9 \pm 1.9) \times 10^{-19} \mathrm{~m}^{3}$, assuming the inner diameter of the nanotube is the same as the diameter of PS template.

The theoretical charge for the 2-electron redox process of PANI Em.salt state is calculated based on the following equation (4) ${ }^{[7 a]}$ :

$$
Q_{\text {tube }}=\frac{\rho V_{\text {tube }}}{M_{\text {unit }}} \text { neN }
$$

where $Q_{\text {tube }}$ is the total charge on an individual tube, $\rho$ equals $1.33 \times 10^{6} \mathrm{~g} \mathrm{~m}^{-3}{ }^{[24]}, V_{\text {tube }}$ represents the volume of a single tube. $M_{u n i t}$ and $n$ are the molecular weight (435 $\mathrm{g} \mathrm{mol}^{-1}$ ) and electron transfer number of each repeat unit (composed of 4 anilines) in a redox reaction, respectively. $n$ equals 2 according to Scheme 1 . $\mathrm{N}$ and e are the Avogadro constant and the elemental charge $\left(=1.602 \times 10^{-19} \mathrm{C}\right)$, respectively. The expected charge is then calculated to be $(171 \pm 112) \mathrm{pC}$.

\section{PANI nanotube coated glassy carbon electrode}

$3.0 \mathrm{~mm}$ diameter glassy carbon working electrode (GCE) supplied by $\mathrm{CH}$ instruments (Austin, TX, USA) was cleaned by polishing with 1.0, 0.3 and $0.05 \mu \mathrm{m} \mathrm{Al}_{2} \mathrm{O}_{3}$ slurry, respectively, and was then sonicated in water and ethanol successively for 2 min in each step. Upon drying with nitrogen, $5 \mu \mathrm{L}$ of freshly prepared PANI nanotube suspensions of $0.3 \mathrm{~g} \mathrm{~L}^{-1}$ was drop cast onto a clean GCE surface. Following drying with nitrogen flow, the PANI nanotube coated GCE is ready to use.

\section{Electrochemical procedures}


Nano-impact chronoamperometry experiments were conducted using a $\mu$-Autolab potentiostat (Autolab, Utrecht, Netherlands) with a conventional three-electrode configuration including a carbon fibre micro wire working electrode, a saturated calomel reference electrode (SCE, BASi, Japan) and a Pt wire counter electrode. It has previously shown experimentally that the similar potentiostat conserves the integral of current though the spikes may be altered ${ }^{[25]}$. A $0.2 \mathrm{M} \mathrm{H}_{2} \mathrm{SO}_{4}$ aqueous solution containing $0.02 \mathrm{~g} \mathrm{~L}^{-1}$ PANI was used as electrolyte in a $10 \mathrm{~mL}$ sample vial $\left(23 \pm 2^{\circ} \mathrm{C}\right)$. Following bubbling with nitrogen for $20 \mathrm{~min}$, chronoamperometric experiments were run at different potentials. The duration for each scan was $50 \mathrm{~s}$. In the interval between the scans, the suspension was deoxygenated with nitrogen for $5 \mathrm{~s}$ to ensure the uniform dispersion of PANI nanotube and to avoid oxygen interfering with the electrochemical reactions. Nitrite aqueous solution was freshly prepared each day.

Cyclic voltammetry (CV) measurements were carried out in a deoxygenated $0.2 \mathrm{M} \mathrm{H}_{2} \mathrm{SO}_{4}$ aqueous solution at $23 \pm 2^{\circ} \mathrm{C}$ using the same three-electrode configuration as above but with a PANI nanotube drop-cast GCE as a working electrode. Each CV scan starts from the OCP of $0.41 \mathrm{~V}$, where the initial Em.salt reacts in a 2-electron reduction process.

\section{Acknowledgments}

This research was partially supported by the European Research Council (ERC) under the European Union's Seventh Framework Programme (FP/2007-2013), ERC Grant Agreement no.320403. The National Natural Science Foundation of China (No. 21476047 and 21776045) is gratefully acknowledged. J. Liu and X. Li thank for the support of the China Scholarship Council.

KEYWORDS Single polyaniline nanotube, nano-impact, charge transfer promotion, nitrite 


\section{References:}

[1] a) B. J. Gallon, R. W. Kojima, R. B. Kaner, P. L. Diaconescu, Angewandte Chemie International Edition 2007, 46, 7251-7254; b) C. O. Baker, B. Shedd, R. J. Tseng, A. A. Martinez-Morales, C. S. Ozkan, M. Ozkan, Y. Yang, R. B. Kaner, ACS nano 2011, 5, 3469-3474; c) D. Li, J. Huang, R. B. Kaner, Accounts of Chemical Research 2008, 42, $135-145$.

[2] a) P. Anilkumar, M. Jayakannan, Langmuir 2008, 24, 9754-9762; b) Y. Yang, Y. Chu, F. Yang, Y. Zhang, Materials Chemistry and Physics 2005, 92, 164-171.

[3] a) H. Dong, S. Prasad, V. Nyame, W. E. Jones, Chemistry of Materials 2004, 16, 371373; b) E. N. Konyushenko, J. Stejskal, I. Šeděnková, M. Trchová, I. Sapurina, M. Cieslar, J. Prokeš, Polymer International 2006, 55, 31-39; c) H. Qiu, M. Wan, B. Matthews, L. Dai, Macromolecules 2001, 34, 675-677.

[4] A. MacDiarmid, J. Chiang, A. Richter, Epstein, AJ, Synthetic Metals 1987, 18, 285290.

[5] A. G. MacDiarmid, A. J. Epstein, Faraday Discussions of the Chemical Society 1989, 88, 317-332.

[6] A. G. MacDiarmid, Angewandte Chemie International Edition 2001, 40, 2581-2590.

[7] a) J. Liu, G. Zhu, X. Li, C. Batchelor-McAuley, S. V. Sokolov, R. G. Compton, Applied Materials Today 2017, 7, 239-245; b) J.-C. Chiang, A. G. MacDiarmid, Synthetic Metals 1986, 13, 193-205.

[8] a) S. K. Simotwo, V. Kalra, Current Opinion in Chemical Engineering 2016, 13, 150160; b) A. Mirmohseni, R. Solhjo, European Polymer Journal 2003, 39, 219-223; c) M. Rahmanifar, M. Mousavi, M. Shamsipur, Journal of Power Sources 2002, 110, 229-232.

[9] a) M. Xin, H. Lin, J. Yang, M. Chen, X. Ma, J. Liu, Electroanalysis 2014, 26, 22162223; b) Yu Gao, Decai Shan, Fei Cao, Jian Gong, Xia Li, Hui-yan Ma, Zhong-min Su, L.-y. Qu, The Journal of Physical Chemistry C 2009, 113, 15175-15181; c) X. Ma, J. Yang, W. Cai, G. Zhu, J. Liu, Chemical Research in Chinese Universities 2016, 32, 702-708; d) S. Bao, M. Du, M. Zhang, H. Zhu, P. Wang, T. Yang, M. Zou, Chemical Engineering Journal 2014, 258, 281-289.

[10] a) Q. L. Hao, X. F. Xia, W. Lei, W. J. Wang, J. S. Qiu, Carbon 2015, 81, 552-563; b) Y.-E. Miao, W. Fan, D. Chen, T. Liu, ACS Applied Materials \& Interfaces 2013, 5, 4423-4428; c) Z.-L. Wang, R. Guo, G.-R. Li, H.-L. Lu, Z.-Q. Liu, F.-M. Xiao, M. Zhang, Y.-X. Tong, Journal of Materials Chemistry 2012, 22, 2401; d) D. Vonlanthen, P. Lazarev, K. A. See, F. Wudl, A. J. Heeger, Advanced Materials 2014, 26, 50955100; e) A. M. Bryan, L. M. Santino, Y. Lu, S. Acharya, J. M. D’Arcy, Chemistry of Materials 2016, 28, 5989-5998. 
[11] a) T. Kobayashi, H. Yoneyama, H. Tamura, Journal of Electroanalytical Chemistry and Interfacial Electrochemistry 1984, 161, 419-423; b) D. Ge, L. Yang, Z. Tong, Y. Ding, W. Xin, J. Zhao, Y. Li, Electrochimica Acta 2013, 104, 191-197.

[12] a) R. J. Tseng, J. Huang, J. Ouyang, R. B. Kaner, Yang, Nano Lett. 2005, 5, 10771080; b) J. Han, L. Li, R. Guo, Macromolecules 2010, 43, 10636-10644.

[13] a) J. Stejskal, J. Prokeš, I. Sapurina, Materials Letters 2009, 63, 709-711; b) G. Chang, Y. Luo, W. Lu, X. Qin, A. M. Asiri, A. O. Al-Youbi, X. Sun, Catalysis Science \& Technology 2012, 2, 800-806.

[14] Y. Cao, P. Smith, A. Heeger, Synthetic Metals 1989, 32, 263-281.

[15] a) B. Donald, J. Gray, L. Gibbins, Journal of Food Science 1980, 45, 893-897; b) P. Morrissey, J. Tichivangana, Meat Science 1985, 14, 175-190.

[16] A. J. Bard, M. Stratmann, F. Scholz, C. J. Pickett, Encyclopedia of Electrochemistry: Inorganic Chemistry, Wiley-VCH Verlag GmbH, Weinheim, Germany, 2006.

[17] a) M. Guo, J. Chen, J. Li, B. Tao, S. Yao, Analytica Chimica Acta 2005, 532, 71-77; b) X. Luo, A. J. Killard, M. R. Smyth, Chemistry-A European Journal 2007, 13, 21382143; c) A. Gopalan, K.-P. Lee, S. Komathi, Biosensors and Bioelectronics 2010, 26, 1638-1643; d) M. Muchindu, T. Waryo, O. Arotiba, E. Kazimierska, A. Morrin, A. J. Killard, M. R. Smyth, N. Jahed, B. Kgarebe, P. G. Baker, Electrochimica Acta 2010, 55, 4274-4280; e) H. Wang, P.-H. Yang, H.-H. Cai, J. Cai, Synthetic Metals 2012, 162, 326-331.

[18] a) W. Cheng, R. G. Compton, Trends Anal. Chem. 2014, 58, 79-89; b) Y.-G. Zhou, N. V. Rees, R. G. Compton, Angew. Chem. 2011, 123, 4305-4307; c) X. Li, C. Batchelor-McAuley, S. A. I. Whitby, K. Tschulik, L. Shao, R. G. Compton, Angew. Chem. Int. Ed. 2016, 55, 4296-4299; d) L. Chen, X. Li, E. E. L. Tanner, R. G. Compton, Chem. Sci. 2017, 8, 4771-4778.

[19] J. De Albuquerque, L. Mattoso, R. Faria, J. Masters, A. MacDiarmid, Synthetic Metals 2004, 146, 1-10.

[20] E. Kazimierska, M. R. Smyth, A. J. Killard, Electrochimica Acta 2009, 54, 7260-7267.

[21] Electroanalytical Chemistry and Interfacial Electrochemistry 1987, 217, 417-423; b) J. Ellison, C. Batchelor-McAuley, K. Tschulik, R. G. Compton, Sensors and Actuators B: Chemical 2014, 200, 47-52.

[22] a) G. D'Aprano, M. Leclerc, G. Zotti, Journal of Electroanalytical Chemistry 1993, 351, 145-158; b) A. Malinauskas, R. Holze, Synthetic Metals 1998, 97, 31-36; c) J. Stejskal, P. Kratochvil, N. Radhakrishnan, Synthetic Metals 1993, 61, 225-231. 
[23] T. Arakaki, T. Miyake, T. Hirakawa, H. Sakugawa, Environmental Science \& Technology 1999, 33, 2561-2565.

[24] J. Stejskal, R. Gilbert, Pure and Applied Chemistry 2002, 74, 857-867.

[25] E. Kätelhön, A. Feng, W. Cheng, S. Eloul, C. Batchelor-McAuley, R. G. Compton, The Journal of Physical Chemistry C 2016, 120, 17029-17034. 
Table of content:

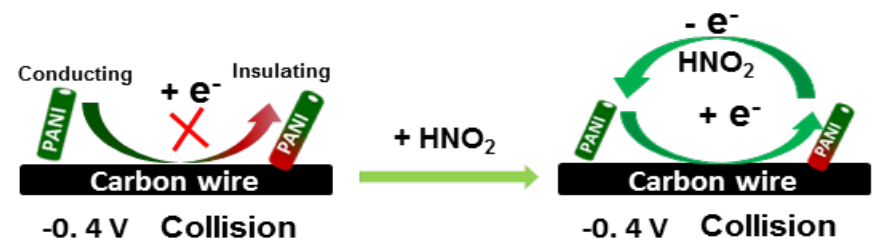

